\title{
V Fórum PPGDT e I Seminário Oeste Metropolitano do Rio de Janeiro: Reflexões em participação social e desenvolvimento territorial: limites, vivências e políticas - Relatoria do Evento Online
}

Dayana Nascimento, Deborah Gaspar, Lara Martins, Larissa David, Paloma Belchior e Valéria Santos

\section{(2) OpenEdition}

\section{Journals}

Edição electrónica

URL: http://journals.openedition.org/espacoeconomia/14881

DOI: 10.4000/espacoeconomia. 14881

ISSN: 2317-7837

Editora

Núcleo de Pesquisa Espaço \& Economia

Refêrencia eletrónica

Dayana Nascimento, Deborah Gaspar, Lara Martins, Larissa David, Paloma Belchior e Valéria Santos, «V Fórum PPGDT e I Seminário Oeste Metropolitano do Rio de Janeiro: Reflexões em participação social e desenvolvimento territorial: limites, vivências e políticas - Relatoria do Evento Online », Espaço e Economia [Online], 19 | 2020, posto online no dia 25 agosto 2020, consultado o 11 setembro 2020. URL : http://journals.openedition.org/espacoeconomia/14881; DOI : https://doi.org/10.4000/ espacoeconomia. 14881

Este documento foi criado de forma automática no dia 11 setembro 2020. 


\section{Fórum PPGDT e I Seminário Oeste Metropolitano do Rio de Janeiro: Reflexões em participação social e desenvolvimento territorial: limites, vivências e políticas - Relatoria do Evento Online}

Dayana Nascimento, Deborah Gaspar, Lara Martins, Larissa David, Paloma Belchior e Valéria Santos

\section{Introdução'}

1 A quinta edição do Fórum do Programa de Pós-Graduação em Desenvolvimento Territorial e Políticas Públicas (V Fórum PPGDT) ocorreu de forma integrada com o I Seminário Oeste Metropolitano do Rio de Janeiro (I SOMRJ), em colaboração do Programa de Pós-Graduação em Geografia (PPGGEO), ambos sediados na Universidade Federal Rural do Rio de Janeiro (UFRRJ), cujas temáticas sobre questões metropolitanas e seus desdobramentos no desenvolvimento dos territórios estruturaram, principalmente a "borda" oeste metropolitana fluminense. O evento objetivou fomentar a integração entre discentes e docentes de ambos programas com a comunidade acadêmica, promovendo diálogos e intercâmbios acerca dos temas das pesquisas aderentes aos dois Programas, principalmente concernentes aos processos de produção e construção do espaço urbano e periurbano, incluindo questões relacionadas ao planejamento e às políticas públicas.

2 Em nossa avaliação, o evento superou as perspectivas dessa integração. Além do grande número de participantes, com mais de 200 inscritos, e pelo aprofundamento das pesquisas, observamos a ressignificação multicultural possibilitada pelos meios digitais, 
recurso último usado no período de pandemia global, ocasionada pela Covid-19, e a necessidade do distanciamento social devido aos seus efeitos. De abrangência internacional, o evento integrado ocorreu entre os dias 15 e 23 de junho de 2020, via webconferência, na plataforma da Rede Nacional de Ensino e Pesquisa (RNP), de caráter gratuito e acessível tanto à comunidade acadêmica quanto ao público em geral. Contou com a participação de palestrantes nacionais e internacionais em conferências e mesas redondas, bem como apresentações temáticas de mestrandos do PPGDT e PPGGEO.

O objetivo geral do V Fórum PPGDT e I SOMRJ foi propiciar a difusão do conhecimento das áreas de Planejamento Urbano e Regional/Demografia (PURD) e da Geografia, para a comunidade acadêmica e o público em geral, promovendo um canal de diálogo com as exposições e os debates. Paralelamente, buscou apresentar os resultados das pesquisas das turmas de mestrado ingressantes em ambos os programas em 2018, englobando outras pesquisas em finalização ou já concluídas até junho de 2020. Além disso, almejou possibilitar o debate e integração entre discentes e docentes do PPGDT, PPGGEO e de outros programas de pós-graduação afins, bem como demonstrar aos discentes veteranos e ingressantes dos Programas o processo de amadurecimento e reflexão da pesquisa acadêmica. Por fim, objetivou trazer para o debate as diversas abordagens e temáticas da área PURD e da Geografia e promover a reflexão sobre o Oeste Metropolitano do Rio de Janeiro (OMRJ) como categoria analítica.

O caráter multicultural do evento ficou latente pelos debates, sendo direcionado aos interessados provenientes dos mais diversos campos do conhecimento, tais como Economia, Arquitetura e Urbanismo, Geografia, Ciências Sociais, História, Direito, Administração Pública, Meio Ambiente e áreas afins, além de profissionais envolvidos nas temáticas propostas nas cinco Mesas Redondas com os temas de:

1) Centralidades e Periferias

2) Participação social, Movimentos sociais

3) História, desenvolvimento e urbanização

4) Limites e Fronteiras: por uma regionalização do Oeste Metropolitano

5) Tramas Políticas e Produção do Espaço

10 O evento no formato online proporcionou ampla participação, alcançando participantes ouvintes de todas as regiões brasileiras, e propiciou a cooperação e a conjectura de palestrantes nacionais e internacionais, com membros da organização do evento, expositores de trabalhos, docentes e discentes de graduação e pós-graduação em diálogos e intercâmbios ricos e com desdobramentos, interfaces regionais e rebatimentos para o OMRJ.

11 Ao final dos cinco dias de debates, fica impresso na memória do evento conjunto a interdisciplinaridade e excelência na composição das várias sessões realizadas, sempre mediadas por um docente de um dos Programas. A pluralidade conceitual e temática e a interlocução entre pesquisadores e representantes da sociedade civil foi também um indicativo da relevância do evento.

12 Este documento busca relatar, então, as atividades realizadas em cada dia do evento, destacando os principais momentos e debates. 


\section{Abertura, Conferências Inaugurais (Dia 1)}

13 O evento teve suas atividades iniciadas com a Mesa Institucional, composta pelo Prof. Alexandre Fortes, representando a Pró-reitoria de Pesquisa e Pós-graduação (PROPPG) da UFRRJ, os Diretores do Instituto de Ciências Sociais Aplicadas (ICSA), Prof. Daniel Ribeiro, e do Instituto de Agronomia (IA), Prof. Alexis Nummer, os Coordenadores do PPGDT, Prof. Vinicius Baptista, e do PPGGEO, Prof. Marcio Rufino Silva, da Coordenadora Geral do Evento, Profa. Denise de Alcântara, e da representante discente do PPGDT, mestranda Lara Mattos. Todos os presentes a essa mesa ressaltaram a importância de sua realização no modo remoto, mantendo ativas as atividades acadêmicas, além de ressaltarem a relevância das temáticas propostas e aproximação com a realidade local e de inserção da instituição, especialmente no momento de pandemia, em que as atividades presenciais encontravam-se suspensas.

14 Após a Mesa Institucional, seguiu-se a primeira Conferência Inaugural, na qual a antropóloga Erika Robb Larkins, Diretora do Behner Stiefel Center for Brazilian Studies da San Diego State University, proferiu palestra sob o título "Profissionais de Segurança - escolta armada e carreira das armas", trazendo um debate em torno da segurança privada. A professora analisou como este setor impacta nas dinâmicas territoriais, problematizando a temática do roubo de cargas, da escolta armada e da militarização e financeirização do espaço urbano; tal apresentação corresponde a um dos capítulos do seu próximo livro, intitulado Guarding Rio de Janeiro - Private Security in Brasil, com previsão de lançamento em 2021. O trabalho etnográfico consiste em 18 meses de pesquisa de campo, como participante em cursos de treinamento de escolta armada, que objetivou analisar como o curso de segurança se estrutura e organiza, quais são as condições de trabalho dos agentes da escolta, como são suas relações e interações sociais e, por fim, como os agentes de segurança se enxergam enquanto membro do contexto de segurança pública. Por fim, Larkins explorou como a interação social na escola de segurança e no local de trabalho molda a subjetividade do vigilante de maneira chave, o que auxilia no entendimento das razões destes homens, provenientes em grande maioria de bairros e regiões periféricas da RMRJ, que optam em trabalhar sobre condições extremas de risco.

O segundo conferencista foi Roberto Monte-Mór, professor do CEDEPLAR-UFMG, que introduziu um debate sobre as oportunidades e ameaças à luz do novo urbano no mundo contemporâneo. Em sua conferência, com base nas ideias de Henri Lefebvre, o professor sugere reflexões sobre o processo de urbanização concentrada e urbanização extensiva, e o surgimento do novo urbano, com fortalecimento de economias alternativas, que o professor denomina "naturalização extensiva", termo que se contrapõe ao processo de "urbanização extensiva". Através das dinâmicas de desenvolvimento territorial, marcado pela era agrária, seguido pela era industrial e em ordem atual, cercado pelo processo de urbanização de nível global, articula uma série de reflexões, sobre o processo de transformação do mundo contemporâneo. Para ele, esse processo de que atinge a sociedade em sua totalidade se organiza em dois pontos: $\mathrm{o}$ primeiro, relativo às oportunidades de articulação, difusão do conhecimento $\mathrm{e}$ organização social, são características importantes que compreendem uma nova ordem de desenvolvimento urbano; o segundo, relativo ao processo de politização do espaço de vida, sobre a premissa da "Revolução Urbana" de Henri Lefebvre, pela qual a sociedade contemporânea se distancia de suas relações iniciais de urbanidade, rumo a 
um novo paradigma menos voltado ao acúmulo de capital e produtividade do espaço urbano, abrindo espaço a novas formas de orientação da vida cotidiana para o centro das preocupações. O Prof. Monte-Mór destaca, ainda, a obra de Henri Lefebvre e o livro "A Grande Transformação", de Karl Polanyi, como referência para o entendimento do processo de urbanização contemporâneo no Brasil e no mundo, e suas significativas transformações desde o século passado. Em sua argumentação, o direito à cidade lefebvriano nos ajuda a entender as interações entre a cidade antiga, ligada à ideia de ruralidade e seu processo de desenvolvimento territorial, apoiado pelo processo de industrialização e a consequente urbanização.

\section{Mesa 1 - Centralidades e Periferias}

16 A primeira Mesa Redonda foi composta pela Prof. Luciana Correa do Lago, da UFRJ, por Henrique Silveira, Coordenador Executivo da "Casa Fluminense", e por Guilherme Braga Alves, Doutorando em Geografia pela UERJ. As abordagens da Mesa se iniciam perpassando pela discussão da cidade e seus conteúdos. A professora Luciana Lago esclarece a ideia central de entendimento à cidade como geradora de conflitos, vida $\mathrm{e}$ trabalho. Henrique Silveira organizou a temática em dois planos: resgate histórico do processo de planejamento da metrópole e uma análise crítica do Plano Estratégico de Desenvolvimento Urbano Integrado da Região Metropolitana do Rio de Janeiro (PEDUIRMRJ) proposto pela Câmara Metropolitana do Rio de Janeiro. A apresentação baseouse em sua vivência como um dirigente da "Casa Fluminense". Em uma abordagem histórica, resgatou os espaços de discussão das políticas públicas da cidade desde os anos 1980, atravessando o hiato dos anos 1990/2000, até a criação da Câmara Metropolitana de Ação Governamental, na função de planejar a RMRJ, elaborar projetos-lei e a planta cartográfica dessa região. Ressalta a elaboração do PEDUI-RMRJ de 2015 a 2018, e a realização a 1 ${ }^{\mathrm{a}}$ Conferência Metropolitana, que abriu, mesmo que de forma incipiente, um espaço de discussão sobre a metrópole. Guilherme Alves apresentou a linha de pesquisa de sua tese de doutorado, que aborda a questão da mobilidade no bairro de Campo Grande, no Rio de Janeiro, que se insere no OMRJ. Em uma perspectiva histórica iniciada no século XIX, aborda o transporte por canais alagáveis e o caminho imperial até a Fazenda Santa Cruz até o século XX, passando por Itaguaí e caminhos para São Paulo. A partir de relatos históricos sob o mote de que "a cidade está chegando", relaciona a construção de estradas de ferro e linhas de bondes por tração animal ao cultivo das laranjas, onde Campo Grande se configura ponto nodal de transportes na metrópole, com dois polos distintos, sul e norte. Sugere construir um OMRJ através das interações sociais da vida urbana.

17 A Profa. Luciana Lago, por sua vez, argumenta a necessidade de se pensar um outro projeto de cidade, já que a perda do direito ao centro ocorre pela construção de parâmetros urbanos difundidos pela burguesia. Os movimentos de resistência às remoções são exemplos da luta pelo direito à cidade. Ela aborda ainda o tema da economia popular como uma temática complexa, demandando pensá-la para além do formato burguês, além das experiências associativas de trabalho e produção que ganham destaque em sua explanação. Sobre Centralidades e Periferias, relaciona o direito à apropriação do espaço pelos territórios populares com intenção de captar movimentos de moradia e coletivos de cultura. A dialética da falta e a potência de territórios populares que surge da carência, configura potência transformadora, por 
meio de ações comunitárias, capacidade organizativa e de agricultura local de pequeno porte. Henrique Silveira questiona se o atual Conselho Consultivo do PEDUI-RMRJ está atendendo aos interesses da população ou do governador ou do empresariado, exemplificando com a questão da privatização da CEDAE. Afirma ainda que não se pode pensar na questão urbana sem falar em relações de trabalho, para produzir uma nova cidade. Guilherme Alves afirma que deve-se ir além dos galpões logísticos, que despreza o trabalho humano e aponta modelos quase sempre individualistas. Para ele, deve-se deixar de enxergar o espaço como espaço dos shoppings e dos motoristas de aplicativos, já presentes no OMRJ.

\section{Dia 2 - Participação Social e Movimentos Sociais}

Dividido em duas sessões, na manhã do segundo dia do evento ocorreu a mesa de Apresentações Temáticas Participação e Inclusão social, com as pesquisadoras Nathália Abreu, Rita de Cássia e Taís Cogo, do PPGDT. As três apresentações tiveram como ponto de interlocução a análise sobre participação social na formação territorial e políticas públicas para reforma agrária e meio ambiente em localidades periféricas, expondo as desigualdades históricas desses territórios sem investimentos em infraestrutura urbana, ressaltando a importância da participação social para a garantia de direitos no que tange acesso à moradia e meio ambiente saudável. Taís Cogo relatou sua experiência em assentamentos rurais, especificamente, o diálogo com a Associação de Camponeses de Marapicu, foco de sua pesquisa intitulada "Invisíveis Perante o Poder Público: O Assentamento Municipal Rural de Marapicu e as Reivindicações de Políticas Públicas para o Território Rural". Na análise de processos identitários, de apropriação simbólica e ações políticas característicos da construção de relações entre os camponeses e a sociedade urbana onde se insere, em distintos contextos históricos, descreveu a formação territorial e a reforma agrária da Baixada Fluminense, por meio do histórico das ocupações das antigas fazendas, contextualizando a Associação de Marapicu na atualidade. Na sequência, a pesquisadora Rita de Cássia apresentou o trabalho: "Diagnóstico Ambiental Participativo como subsídio para avaliação da segurança alimentar, hídrica e energética - estudo de caso em Angra dos Reis, RJ", cujo objetivo foi propor metodologias participativas para avaliação integrada do nexo águaalimento-energia em áreas urbanas, apontando a sustentabilidade como importante ponto reflexivo, como resultado da espacialidade, da reestruturação, transmutação e síntese da sociedade com a paisagem. Analisa o histórico das transformações no uso do solo em Bracuí, destacando a desigualdade socioespacial, problemas urbanos e ambientais e os conflitos por terra no lugar. A terceira apresentação foi a da mestranda Nathália Abreu, intitulada "Avaliação de Impactos de Políticas Públicas de Saneamento Básico na Baixada Fluminense", na qual aponta uma relação de causalidade entre o avanço do processo de urbanização e segregação espacial na Baixada Fluminense, com a degradação ambiental e desigualdade social em relação ao núcleo da metrópole. Demonstra que o território e a população vivenciam problemas ambientais ligados aos baixos índices de infraestrutura urbana, à concentração de atividades econômicas poluentes e à pobreza, sendo reconhecida como zona de sacrifício, apontando o passivo ambiental relacionado à poluição dos corpos hídricos, a falta de políticas públicas de saneamento básico, e ao legado histórico de exclusão das parcelas mais pobres e vulneráveis da população. 
19 A Mesa 2 - Movimentos Sociais e Participação Social, contou a participação da Dra. Giselle Tanaka, professora do IPPUR e de Mauro Pereira, Biólogo e integrante do Movimento de Defesa da Baía de Sepetiba - Agenda 2030.

20 A Profa. Giselle Tanaka apresentou o tema "Movimentos Sociais Urbanos e Participação Social no Brasil", iniciou o debate com um resgate histórico sobre os movimentos sociais que emergiram no Brasil, sobretudo a partir da década de 1970, originadas nas primeiras organizações de bairros populares que reivindicavam transporte e regularização fundiária, e os desdobramentos ao longo dos anos. A partir da década de 1980 , as organizações de bairro adentram no cenário público, questionando o regime ditatorial e levando à dimensão nacional a luta por moradia e pela organização territorial. Sua principal reflexão aponta que a desigualdade sócio-territorial pouco se alterou no decorrer dos últimos anos, tendo como consequência o acentuado grau da segregação sócio-espacial e aumento expressivo da informalidade nas periferias. Destaca a informalidade não como resultado da pobreza ou como resultado das condições precárias que vão sendo acumuladas pela população, mas como resultado de uma política de Estado. Assim, a palestrante resgata as contribuições de Ananya Roy, onde a informalidade é uma categoria gerada pelo próprio Estado, que determinará os limites da formalidade e informalidade na cidade, cuja construção passa a ser conduzida a partir da produção formal e do mercado imobiliário, e não pelas demandas dos habitantes.

21 Mauro Pereira iniciou sua explanação sobre a Baía de Sepetiba como um local de pescadores e de comunidades tradicionais que, no decorrer do tempo, transformou-se em zona de sacrifício, para onde se desloca o "progresso" e o "desenvolvimento" econômico, o que resultou nos altos níveis de poluição na baía. Tais ações se dão, inicialmente, pela liberação de instalação de indústrias de alto impacto ambiental em uma região com mais de 3 milhões de habitantes, que, até hoje não dispõem de água potável e saneamento básico. Em 10 anos, o território com importante aporte turístico, artesanal e cultural perdeu grande parte de seus atributos. Para ele, o poder público, visando o progresso, planejou a entrada das indústrias sem olhar as especificidades do território em si, nem das pessoas que lá vivem.

Em síntese, as duas mesas debateram a formação dos territórios industriais e urbanos fora do núcleo metropolitano, ressaltando a participação social como contraponto e a percepção dos cidadãos na falta de infraestrutura e descuido do poder público para com o meio ambiente e garantia de direitos básicos, como terra e saneamento básico.

\section{Dia 3 - História, Desenvolvimento e Urbanização}

23 A manhã do terceiro dia do evento iniciou-se como a segunda mesa de Apresentações Temáticas, intitulada, Produção do Espaço, tendo os mestrandos Daniele Leão, Raul Oliveira e Patrícia Barcelos, do PPGDT, e André Germano, do PPGGEO, como palestrantes. A mesa abordou a importância dos grandes empreendimentos como agentes indutores da produção do espaço, seja por meio da implantação de uma grande indústria, ou pela presença de uma universidade com suas ações de pesquisa e extensão no espaço, ou ainda, a produção do espaço pela institucionalização por meio do Direito. Mostraram-se relevantes as questões sobre a localização estratégica de implantação de grandes empreendimentos produtivos, tendo como empiria os processos de industrialização do Bairro de Santa Cruz, Município do Rio de Janeiro, e a cidade de 
Barra Mansa, na microrregião do Médio Vale do Paraíba. Emergiram questões sobre a institucionalização dos territórios por meio do Direito e a ruptura da "centralidade econômica" com criação das "multicentralidades". A presença de instituições de ensino, como a UFRRJ, em Seropédica, RJ, foi destacada pelas pesquisas capazes de interferir na realidade local, e na reestruturação territorial e produtiva do OMRJ.

Foram ainda apontados os problemas causados pela implantação de atividades industriais que impactaram econômica, socioespacial e ambientalmente os espaços em análise, intensificando as disputas inter-regionais, tratadas como "guerra dos lugares"; as dificuldades de distribuição do poder dentro do território no atual modelo de Estado Democrático de Direito adotado no Brasil; a apropriação pelo capital do discurso sobre sustentabilidade; e a periferização da periferia, evidenciando as profundas mudanças do rural e do urbano em consequência da especialização capitalista do espaço. As tendências destacaram a contribuição multidisciplinar principalmente com as contribuições da geografia e da economia, perpassando pela análise histórica de constituição dos territórios estudados, contando ainda com as contribuições da sociologia, da ciência política, entre outras, e a criação espaços experimentais como laboratório de pesquisa, presentes no estudo de campo. Como questões que emergiram destes temas, destacam-se os resultados positivos das ações participativas e a ainda precária articulação, no Brasil, entre os poderes público e privado. Levantou-se a necessidade de incorporar aos projetos não apenas dados técnicos, mas também aspectos subjetivos relacionados às noções de identidade da população. As perspectivas dos trabalhos apontam para a necessidade de consideração das espacialidades criadas e recriadas pelo modo produção capitalista, aliando maiores entendimentos sobre o conceito de região e a necessidade da interação das pesquisas acadêmicas com a sociedade.

O segundo momento do dia, na parte da tarde, foi regido pelas discussões da Mesa 3 "História, desenvolvimento e urbanização" apresentada pela Dra. Manoela Pedroza, da Universidade Federal Fluminense; por Pablo Ramoz, ativista e curador cultural, do Movimento Santa Cruz 2030; e pelo Dr. Leandro Dias de Oliveira, professor da UFRRJ. 0 rico debate se centrou nos seguintes tópicos: resgate histórico do processo de formação do espaço a partir da Fazenda Santa Cruz; reestruturação territorial e produtiva do OMRJ, elencando as principais mudanças causadas pela industrialização na região e nas alterações ocorridas no rural e o urbano; transformações ambientais, resultado de um discurso de sustentabilidade nada sustentável; tensões políticas em curso no território; "periferização da população da periferia"; e, finalmente, tensões sociais existentes entre as comunidades tradicionais e a especialização capitalista do espaço, tendo com exemplos práticos o surgimento dos condomínios fechados, o Comperj e o Arco Metropolitano.

Mostraram-se relevantes as questões sobre a especulação imobiliária e disputa por terras a partir de uso, mas sem documentos de propriedade, a desvalorização do solo na produção agrícola, e da mão de obra da população da periferia, com agravamento da falta de diálogo entre a comunidade e os empreendimentos industriais, onde a população não se reconhece e não é bem-vinda. Aventou-se a possibilidade de inversão do desenvolvimento proposto (top-down) pela ação coletiva Santa Cruz 2030 e a necessidade de fortalecimento da sociedade civil organizada e de sua proximidade com as empresas em busca do bem viver. 
27 Foram ainda apontados os problemas causados pela implantação de grandes empreendimentos industriais que impactaram econômica, socioespacial e ambientalmente nos espaços, a reestruturação territorial e produtiva do OMRJ, focado no processo de industrialização de Santa Cruz, causando profundas alterações no rural e no urbano e promovendo transformações socioambientais do território, descentralizado, estratificado, fragmentado, segregado e cada vez mais especializado em consequência da ação do capital.

As tendências destacaram a contribuição multidisciplinar através de workshops promovidos por entidades como a Casa Fluminense, com participação da população, estudantes, pesquisadores, entre outros, e a criação espaços de discussão dos assuntos importantes para as comunidades que recebem os empreendimentos e que não se vêm parte deles, promovendo a interação principalmente pela capacitação cultural e educacional.

Destaca-se a validade dos diagnósticos para a necessidade de um planejamento sustentável, aliado a um projeto de redução das distinções sociais e que possibilite maior entendimento metropolitano, melhores fluxos e diálogos entre a sociedade civil e os distritos industriais, com apoio à produção econômica e cultural local, além da promoção do desenvolvimento local.

\section{Dia 4 - Limites e Fronteiras: é possível uma regionalização do Oeste Metropolitano?}

30 A primeira sessão de Apresentações Temáticas "Políticas Públicas e Segregação Socioespacial", foi composta pelos mestrandos Juliana Santos, Flavia Souza e Miguel Pinho, do PPGGEO, que centraram suas abordagens no desenvolvimento econômico regional, nas desigualdades habitacionais e na falta de implementação de políticas públicas de saneamento básico. O debate focou na mercantilização da água e a crise hídrica do Rio Guandu, exemplificando a problemática ambiental por contaminação de esgoto in natura devido às condições sociais desiguais; a contaminação pode ocorrer pela falta de acesso ao saneamento básico da classe periférica, que não dispõe capital financeiro para adquirir imóveis nos centros urbanos. Percebe-se que as políticas públicas de saneamento básico funcionam, em sua grande parte, para sociedade de classe média, ou para as elites. A discussão questionou se há ou são eficientes as políticas públicas implementadas para solucionar os problemas ambientais e segregação socioespacial.

31 Logo depois, o desenvolvimento econômico veio à pauta, centrado na ideia da construção do Distrito Industrial de Queimados, caracterizado pelas parcerias com o governo estadual, com redução do ICMS e grandes investimentos. O desenvolvimento econômico de Queimados se ampara em empresas do ramo da construção civil; na indústria de transformação e indústria extrativista. O distanciamento da dinâmica urbana e a queda das atividades industriais, entre os anos de 2016 e 2017, retrocederam a atividade para níveis pré-processo de reestruturação, fenômeno que está associado ao fim das grandes obras do Estado e a falta de investimentos públicos e dos financiamentos imobiliários do Programa Minha Casa, Minha Vida (PMCMV).

O PMCMV foi o tema seguinte, pontuando a desigualdade nas políticas habitacionais e o aprofundamento dos problemas de moradia nos espaços periféricos com a promoção da 
implementação de habitações, desassociadas à demanda e à moradia digna. A interiorização da construção das casas em massas traz o questionando sobre o tipo de público ao qual se destina, as faixas de renda e as diferenças espaciais de localização dos condomínios, concluindo-se que a política de endividamento e produção de casas em massas desconsidera a realidade dos espaços periféricos. Assim, o modelo do Programa Minha Casa Minha Vida não pode ser considerado como uma produtor de moradia digna que cumpra as funções necessárias para realização da vida plena, gerando um fator de reprodução da segregação e intensificação das desigualdades. Por fim, a discussão dos temas abordados traz uma reflexão acerca da reformulação dessas políticas públicas, de forma que, possam gerar soluções concretas aos problemas públicos levantados, com aspectos mais objetivos.

À tarde, deu-se a Mesa 4 - "Limites e Fronteiras: é possível uma regionalização do Oeste Metropolitano?" composta pelos professores da UFF, Dra. Rita de Cássia Montezuma, do campus Praia Vermelha, e Dr. Leonardo Santos, do campus de Campos dos Goytacazes, e Dr. Marcio Rufino Silva, professor da UFRRJ. Os debates centraram na contextualização e problematização da regionalização do OMRJ.

A Profa. Rita Montezuma instigou a compreensão dos parâmetros que definem os limites e fronteiras, a partir dos aspectos geobiofísicos; considerando a conformação geomorfológica da região. Boa parte do atual território dos municípios da RMRJ se desenvolveu em áreas alagadiças, condicionada e exposta às interações físico-químicas e biológicas, espelhadas naqueles ecossistemas. A partir do comportamento climático e da distribuição da água de chuva é possível determinar a conformação da região que é também definida pela sociobiodiversidade, ou seja entre diversificação biológica, humana e cultural. Assim, a interação entre indivíduos e meio ambiente irá produzir outras tipologias e variedades, imprimindo de forma ampla a diversidade de paisagens e biomas. O espaço geográfico passa a ser um produto dessa interação. A RMRJ é delimitada pela ocupação e interação humana e por seus recursos ambientais, pela intencionalidade, pela temporalidade e pela cultura. $O$ capital, modo de produção, no período atual, propõe outra forma de desenvolvimento, invertendo os valores de natureza, de valor de uso para valor de troca; redefine a organização espacial, modificando seus os limites.

o Prof. Leonardo Santos foca em como a Zona Oeste do município do Rio de Janeiro, um recorte do OMRJ, é pensado no projeto de regionalização e desenvolvimento, com enfoque na linha sócio-histórica. A Zona Oeste foi se modificando, sendo conhecida como "sertão carioca", e tendo a presença de muitos grupos significativos que desempenham até hoje atividades de agricultura urbana e rural. É interessante observar a existência de vastas áreas agrícolas, que, paradoxalmente, parecem invisíveis e geralmente não são associadas à imagem do Rio de Janeiro. Ao observar a historicidade local, o professor argumentou que não se pensou em políticas públicas agrícolas que pudessem se desenvolver no Zona Oeste, sendo sempre essa região pensada como "terreno baldio", sem uma clara ou justa regulação da propriedade, ou apenas um cinturão verde ao redor da cidade. Após um longo período, o poder público repensa essa área como outras formas de desenvolvimento de expansão, realocando comunidades de baixa renda para outros locais de forma incisiva. Desta forma, se faz necessário a reflexão da necessidade de políticas públicas agrícolas e fundiárias, pensando a agricultura com papel efetivo no desenvolvimento. 
O Prof. Marcio Rufino Silva teve como objetivo pensar uma perspectiva de regionalização a partir de recortes específicos a sub-região OMRJ. Sua apresentação pontuou questões referentes à regionalização local e sua relação com a RMRJ, uma vez que sua concepção de OMRJ engloba municípios já presentes em outras subdivisões, como no caso da Baixada Fluminense e, como região se relacionaria com as políticas públicas (em nível municipal, estadual e federal). Para tanto, em sua apresentação, apresentou uma cartografia de diversos agentes regionalizadores, como o Comitê de Bacia Hidrográfica Guandu, a Secretaria de Estado de Meio Ambiente e Desenvolvimento Sustentável, o Plano Estratégico de Logística de Cargas do Estado do Rio de Janeiro (PELC/RJ 2045), o PEDUI-RMRJ 2018, entre outros. Enfatizou, também, a perspectiva regionalizadora do "Sertão Carioca", apresentada por Armando Magalhães Corrêa, e a da "Baixada de Sepetiba", apresentada pelo engenheiro Hildebrando de Góes, ambas concebidas entre as décadas de 1930 e 1940. Além disso, em uma visita à história do que se propõe hoje ser o OMRJ, apontou elementos da gênese da propriedade, enfatizando a presença da Fazenda Santa Cruz e como essa figura foi mobilizada e ressignificada, ao longo dos séculos, como instrumento de poder e, inclusive, planejamentos vários e, ao longo do século XX, para atender aos projetos de colonização. Na perspectiva do professor, aliás, a instalação de núcleos de colonização são o prelúdio de um processo de urbanização e metropolização que, nos últimos 40 anos do século XX, pouco a pouco consolida-se na região. Desta forma, é fundamental conhecer a realidade e as particularidades do local para se pensar perspectivas de um desenvolvimento ou de se lidar com as questões positivas e negativas da localidade, para que, assim, possam se promover projetos que, de fato, desenvolvam essa região.

\section{Dia 5 - Tramas Políticas e Produção do Espaço}

O último dia do Fórum abrigou debates e rebatimentos apontados durante as falas da Mesa 5 - Tramas Políticas e Produção do Espaço, composta pelo Prof. Maurílio Botelho, da UFRRJ, Prof. Paulo Henrique Barata, SEEDUC-RJ e M.Sc. Carlos Eduardo de Souza (SME-RJ). As discussões tiveram como elemento comum a problemática da produção do espaço na Zona Oeste (ZO) do Rio de Janeiro. Os participantes da Mesa se articularam no sentido da discussão do processo de neoliberalismo que vem afetando os territórios da ZO, conjecturado em diferentes períodos por diferentes agentes que imprimiram na região o seu projeto de (re)construção de centralidades e de ocupação.

o Prof. Maurílio Botelho abordou a problemática da desagregação social e política recorrente em bairros periféricos como Campo Grande e Santa Cruz, do Rio de Janeiro, em que a falta ou ineficiência de atuação do poder público torna a região um terreno fértil para o fortalecimento de grupos religiosos e os ligados a milicianos, sendo elemento comum entre ambas, o fato de que são responsáveis pela modificação dos espaços urbanos e pela constituição de um poder paralelo ao Estado. Atenta-se para o fato de que essas entidades, ao oferecerem serviços, tais como o de assistência social, pelas igrejas majoritariamente neopentecostais, e o de "privatização" da segurança pública, pelos grupos milicianos - direitos que deveriam ser de atribuição do Estado, mas que em áreas mais carentes não ocorre de forma eficiente - esses grupos acabam substituindo o poder público e se tornam uma espécie de poder paralelo. Com isso, ganham cada vez mais força e conseguem imprimir um projeto político naqueles territórios destituídos do Estado, e se lançam na arena política elegendo representantes 
de discurso conservador e religioso com a defesa de desmonte de qualquer forma de regulação, com o objetivo de dar livre curso ao mercado, das instituições particulares e da segurança privada.

o Prof. Paulo Barata trouxe um breve, mas engajado relato, como proposta de apresentação dos cem anos dos agentes sociais e das políticas público-privadas que atuaram na produção do espaço do bairro de Campo Grande, município do Rio de Janeiro. Abordou sua história, observando os atores envolvidos e suas especificidades durante o desenvolvimento rural-agrícola e urbano-industrial durante o século XX, para entender como a formação do bairro como é hoje, e favorecendo vislumbrar algumas possibilidades da produção desse espaço no futuro. Por meio da exposição do contexto histórico do bairro, expôs algumas provocações, considerando como fonte as relações clientelistas e coronelistas da primeira metade do século XX e as relações patrimonialistas e de controle políticos e econômicos que marcaram o surgimento do processo de urbanização e industrialização no início da segunda metade do século XX. Levantou ainda algumas questões que enriqueceram o debate sobre a problemática da produção do espaço: provocando os ouvintes a refletirem sobre: a) o impacto dessas relações de poder para o desenvolvimento local; b) as estratégias utilizadas para o desenvolvimento territorial; e, por fim, c) como as relações entre grupos de interesses diferentes e a sociedade civil interagem no âmbito de um contexto de poder político extremo?

Tais questionamentos estiveram também presentes na palestra de Carlos Eduardo de Souza, que durante a sua apresentação fez um retrato histórico-geográfico da formação do bairro de Campo Grande, observando a questão das transformações espaciais que ocorreram e que vem ocorrendo recentemente no bairro. Souza fez uma reflexão sobre o território e a produção do espaço, a partir de um processo histórico-geográfico de planejamento do poder público, de agentes fundiários e imobiliários na promoção de sub-centralidades e construção do espaço. Ele pontuou que acontecimentos como o fim dos ciclos dos laranjais, o início do processo de loteamentos, o projeto político de modernização e a construção de uma sub-centralidade regional, dentre outros processos pontuados ao longo de sua fala foram responsáveis pela modificação da paisagem, do espaço e da população que ali habitava. Além de uma perspectiva histórico-geográfica de produção do espaço, ele abordou o atual projeto político de criação de uma nova sub-centralidade, viabilizada com a construção do West Shopping, que modificou toda a estrutura em seu entorno, favorecendo a criação de uma rede de serviços, comércios e moradias não existentes até então naquele trecho. Destacou que, para atender a essa nova dinâmica econômica, formou-se todo um núcleo secundário, um subcentro do bairro dotado de um circuito inferior da economia que tirou proveito do shopping.

41 Em suma, os debates realizados na Mesa 5 se questionaram a produção do espaço na Zona Oeste, principalmente no bairro de Campo Grande, procurando articular em que medida diferentes agentes conseguiram imprimir na região um projeto político, de organização e de ocupação dos espaços urbanos.

\section{Considerações Finais}

O V Fórum PPGDT e o I SOMRJ, em colaboração com o PPGGEO, nos cinco dias de sua realização, propiciou e fomentou reflexões sobre os conceitos de cidade, urbanização e 
desenvolvimento, articulando a incidência desses paradigmas na regionalização do OMRJ enquanto categoria analítica.

Inicialmente pensado como evento presencial, que seria realizado na última semana de abril de 2020 na UFRRJ, Campus Seropédica, com todos convites feitos e aceitos, teve que ser reformulado para a versão online, por videoconferência. 0 grande desafio dessa mudança repentina, ocasionada pela pandemia do Covid-19, foi também um grande aprendizado e texto de resiliência de toda a equipe envolvida em sua realização, formada principalmente pelas mestrandas, autoras deste relatório, e pelos docentes do PPGDT, Dra. Denise de Alcantara, e do PPGGEO, Dr. Marcio Rufino Silva. O apoio técnico contou com estudantes de graduação, Jonatha Santos e Larissa Brandão. A confecção deste relatório também contou com a colaboração dos mestrandos Allan Moreira, Eloir Bravim, Antônio Miranda, Gabriel Landim, Lucas Figueiredo, Ingrid Nascimento, Vladimir Rodrigues, Thiago Rodrigues, aos quais somos muito gratas.

Destaca-se a geomorfologia da RMRJ, como fundamental elemento delimitador geobiofisico, assim como a própria ação do homem em sua interação com a natureza, modificando e transformando a todo momento os territórios e suas atividades. Como capital financeiro, inverte os valores do que é natureza, transpassando seu valor de recurso para mercantilização. Os projetos de desenvolvimento industrial planejados para região se utilizam dos recursos naturais e da localização estratégica desse território para fomentar a indústria; não viabiliza o desenvolvimento econômico e sustentável para a população local, aprofundando a dependência da população do núcleo metropolitano. A ocupação desse território foi encadeada com políticas de exclusão socioeconômica e dependência dos aparelhos de estado da Capital.

Em sua construção, os territórios do OMRJ não foram planejados para abrigar as atividades agrícolas de pequenas comunidades, porém a área rural se desenvolve a partir da falta de interesse do poder público em fomentar políticas públicas para o desenvolvimento da agricultura nesse espaço. As comunidades agrícolas carecem de políticas fundiárias que lhes garanta a posse da terra e seus direitos que possibilitariam o crédito. Assim, o reordenamento do território é repensado para a expansão habitacional e para a implantação de polos industriais em detrimento da produção agrícola.

Os debates que ocorreram durante o evento abordaram ainda a formação histórica e geográfica do OMRJ, expondo sua importância nas dinâmicas socioambientais e econômicas em relação ao núcleo metropolitano. METR.Por fim, a realização do evento de abrangência internacional - possibilitada pelo formato remoto - favoreceu a aproximação da comunidade acadêmica e do público interessado nas temáticas abordadas, trazendo à luz e integrando estudos, investigações e pesquisas teóricos e empíricos sobre os espaços, territórios e territorialidades, principalmente no OMRJ, promovendo e valorizando o papel da Ciência e da Universidade Pública no Brasil.

\section{Agradecimentos}

47 Agradecemos às coordenações do PPGDT e ao PPGGEO, da UFRRJ, pelo apoio em todo o processo de elaboração da proposta, planejamento e realização do V Fórum PPGDT e I SOMRJ, bem como aos professores Denise de Alcantara e Marcio Rufino Silva pela coordenação geral do evento, pelo estímulo à ação em momento tão delicado e pelas contribuições na revisão deste Relatório. Agradecemos, igualmente, às professoras e 
professores André Santos da Rocha, Cristhiane Amâncio, Márcio de Albuquerque Vianna, Raquel Pereira de Souza, Lúcia Helena Pereira da Silva, Tatiana Cotta, Denise de Alcantara e Ana Paula Perrota Franco pela mediação das mesas redondas e apresentações temáticas. O presente trabalho foi realizado com apoio da Coordenação de Aperfeiçoamento de Pessoal de Nível Superior - Brasil (Capes), Código de Financiamento 001.

\section{NOTAS}

1. Os mestrandos a seguir atuaram como relatores colaboradores nas mesas temáticas do evento: Allan Moreira, Eloir Bravim, Antônio Miranda, Gabriel Landim, Lucas Figueiredo, Ingrid Nascimento, Vladimir Rodrigues, Thiago Rodrigues.

\section{RESUMOS}

Este trabalho relata a realização do V Fórum do Programa de Pós-Graduação em Desenvolvimento Territorial e Políticas Públicas, e do I Seminário Oeste Metropolitano do Rio de Janeiro, que ocorreram conjuntamente e em colaboração do Programa de Pós-Graduação em Geografia, ambos da Universidade Federal Rural do Rio de Janeiro. Foram abordadas temáticas sobre questões metropolitanas e seus desdobramentos no desenvolvimento dos territórios, principalmente os do Oeste Metropolitano. Realizado remotamente por videoconferências, o evento conjunto fomentou a integração entre discentes e docentes de ambos os programas e a comunidade acadêmica, e promoveu diálogos e intercâmbios acerca dos temas das pesquisas aderentes aos dois Programas, principalmente concernentes aos processos de produção e construção do espaço urbano e periurbano, incluindo questões relacionadas ao planejamento e às políticas públicas. De abrangência internacional, durante os cinco dias do evento foram realizadas conferências e mesas redondas com palestrantes nacionais e internacionais e apresentações temáticas, onde mestrandos e recém-mestres apresentaram suas pesquisas. Em todos os momentos, foi estimulada a interlocução com o público, enriquecendo o debate. 0 evento correspondeu aos objetivos propostos, aprofundando as reflexões sobre a conceituação de Oeste Metropolitano do Rio de Janeiro, pensado como categoria analítica, bem como sobre o desenvolvimento territorial e local e suas interfaces e rebatimentos regionais.

This paper reports the realization of the V Forum of the Graduate Program in Territorial Development and Public Policies, and of the I Metropolitan West of Rio de Janeiro Seminar, which occurred jointly and in collaboration with the Postgraduate Program in Geography, both at the Federal Rural University of Rio de Janeiro. Metropolitan themes and issues and their consequences on the development of territories were addressed, especially those related to the Metropolitan West of Rio de Janeiro. Held remotely by videoconferences, the joint event fostered 
the integration between students and faculty from both programs and the academic community, and promoted dialogues and exchanges about the research topics adhering to the two Programs, mainly concerning the processes of production and construction of the urban and peri-urban space, including issues related to planning and public policies. International in scope, during the five days of the event, conferences and round tables were held with national and international speakers and thematic presentations, where master students presented their research. At all times, dialogue with the public was encouraged, enriching the debate. The event corresponded to the proposed objectives, deepening reflections on the conceptualization of Metropolitan West, thought as an analytical category, as well as on territorial and local development and its interfaces and regional repercussions.

Cet article rend compte de la réalisation du V Forum du Programme d'Études Supérieures en Développement Territorial et Politiques Publiques, et du I Séminaire Ouest Métropolitain de Rio de Janeiro, qui a eu lieu conjointement et en collaboration avec le Programme d'Études Supérieures en Géographie, tous les deux de l'Université Fédérale Rurale de Rio de Janeiro. Des problématiques thématiques sur les enjeux métropolitains et leurs conséquences sur le développement des territoires ont été abordées, notamment celles de l'Ouest Métropolitain. Organisé à distance par visioconférences, l'événement conjoint a favorisé l'intégration entre étudiants et professeurs des deux Programmes et de la communauté académique, et a également favorisé des dialogues et des échanges sur les thèmes de recherche adhérant aux deux programmes, concernant principalement les processus de production et de construction de l'espace urbain et périurbain, y compris les questions liées aux politiques publiques et à la planification. De portée internationale, pendant les cinq jours de l'événement, des conférences et des tables rondes ont été organisées avec des intervenants nationaux et internationaux et des présentations thématiques, où des étudiants de master et de récents masters ont présenté leurs recherches. En tout temps, le dialogue avec le public a été encouragé, enrichissant le débat. En général, l'événement a correspondu aux objectifs proposés, approfondissant les réflexions sur la conceptualisation de l'Ouest Métropolitain de Rio de Janeiro, pensé comme une catégorie analytique, ainsi que sur le développement territorial et local et ses interfaces et répercussions régionales.

Este texto informa sobre la realización del V Foro del Programa de Posgrado en Desarrollo Territorial y Políticas Públicas, y del I Seminario Oeste Metropolitano de Río de Janeiro, que se han realizado en conjunto y en colaboración con el Programa de Postgrado en Geografía, ambos de la Universidad Federal Rural de Río de Janeiro. Se abordaron temas sobre cuestiones metropolitanas y sus consecuencias en el desarrollo de los territorios, especialmente los del Oeste Metropolitano. Realizado de forma remota mediante videoconferencias, el evento conjunto propició la integración entre estudiantes y profesores de ambos programas y la comunidad académica, y promovió diálogos e intercambios sobre los temas de investigación adheridos a los dos Programas, principalmente en los procesos de producción y construcción del espacio urbano y periurbano, incluidos los temas relacionados con las políticas públicas y la planificación. De alcance internacional, durante los cinco días del evento se realizaron conferencias y mesas redondas con ponentes nacionales e internacionales y presentaciones temáticas, donde estudiantes de maestría y maestros recientes presentaron sus investigaciones. En todo momento se fomentó el diálogo con el público, enriqueciendo el debate. El evento correspondió a los objetivos propuestos, profundizando las reflexiones sobre la conceptualización de Oeste Metropolitano de Río de Janeiro, pensado como categoría analítica, así como sobre el desarrollo territorial y local y sus interfaces y repercusiones regionales. 
ÍNDICE

Mots-clés: V Forum PPGDT ; I Séminaire Ouest Métropolitain de Rio de Janeiro ; développement territorial ; production de l'espace ; UFRRJ.

Keywords: V PPGDT Forum; I Metropolitan West of Rio de Janeiro Seminar; territorial development; production of space; UFRRJ.

Palabras claves: V Foro PPGDT; I Seminario Oeste Metropolitano de Río de Janeiro; desarrollo territorial; producción del espacio; UFRRJ.

Palavras-chave: V Fórum PPGDT; I Seminário Oeste Metropolitano do Rio de Janeiro; desenvolvimento territorial; produção do espaço; UFRRJ.

\section{AUTORES}

\section{DAYANA NASCIMENTO}

Mestranda do Programa de Pós-Graduação em Desenvolvimento Territorial e Políticas Públicas. E graduada em Administração Pública pela Universidade Federal Rural do Rio de Janeiro. E-mail: dayanascimento91@gmail.com.

\section{DEBORAH GASPAR}

Professora de Matemática. Aluna do Curso de Pós-Graduação em Geografia da Universidade Federal Rural do Rio de Janeiro. Membro do grupo de pesquisa: Para uma crítica da Economia Política do Espaço, do(a) Universidade Federal Rural do Rio de Janeiro. Possui Pós- Graduação (Latu Sensu) em Novas Tecnologias no Ensino da Matemática, pela Universidade Federal Fluminense, UFF, (2010). Graduada em LICENCIATURA PLENA EM MATEMÁTICA pela Universidade Federal Rural do Rio de Janeiro, UFRRJ, (2006). E-mail: deboragirassol@gmail.com.

\section{LARA MARTINS}

Mestranda no Programa de Pós-Graduação em Desenvolvimento Territorial e Políticas Públicas PPGDT/UFRRJ, bolsista CAPES, pós-graduada MBA em Meio Ambiente e Desenvolvimento Sustentável, pela Universidade Candido Mendes e possui bacharelado em ciências sociais pela Universidade Federal do Espírito Santo - UFES. Realiza pesquisas sobre desenvolvimento, meio ambiente e políticas públicas. E-mail: laramattos.martins@gmail.com.

\section{LARISSA DAVID}

Mestranda no Programa de Pós-Graduação em Desenvolvimento Territorial e Políticas PúblicasPPGDT UFRRJ. E-mail: larisdavi@gmail.com.

\section{PALOMA BELCHIOR}

Mestranda em Desenvolvimento territorial e Políticas Públicas pela Universidade Federal Rural Do Rio de Janeiro. Graduada em Ciências Econômicas pela Universidade Federal Fluminense. Pesquisadora na área de Ciências Sociais Aplicadas com foco nos Programas de Transferência de Renda Condicionas. Bolsista CAPES. E-mail: palomabbsiqueira@gmail.com.

\section{VALÉRIA SANTOS}

Mestranda em Desenvolvimento Territorial e Políticas Públicas - PPGDT/UFRRJ. Graduada em Ciências Econômicas pela Universidade Federal Rural do Rio de Janeiro. Experiência profissional como Analista Imobiliário da Companhia Siderúrgica Nacional (2004-2014), atuando na 
administração dos imóveis operacionais e não-operacionais da empresa. E-mail: valbraga2004@gmail.com. 